\title{
A Study on the Usage Behavior of Middle-level Staff of Buddhist and Pali University on Facebook
}

\author{
Damayanthi Gunasekera ${ }^{1}$ and Manori Samarakoon ${ }^{2}$
}

\begin{abstract}
The use of social media has increased in the recent era compared to the past. Social media is the collection of tools and, online spaces available for communication among individuals and groups. Easy access and accessible communication facilities, flexible languages, and ability to create free accounts are the main reasons for the popularity of Facebook (FB) among nations worldwide, including Sri Lankans. The library of the Buddhist and Pali University (BPU) of Sri Lanka wants to introduce online user groups to communicate and share library-related information through FB. Currently, Wi-Fi facilities are used to communicate with academic staff and higher-level administrative staff. Hence the problem affected was that the behaviour of the non-academic middle-level staff in an online environment is not understood. The primary objective of the study is to understand the behavior of the university non-academic middle-level staff in an online environment before introducing an online communication
\end{abstract}

\footnotetext{
${ }^{1}$ Senior Assistant Librarian, The Open University of Sri Lanka.

Email: hpsgun@ou.ac.lk iD https://orcid.org/0000-0002-0206-1857

${ }^{2}$ Senior Assistant Librarian, Buddhist and Pali University of Sri Lanka.

Email: manori@bpu.ac.lk iD https://orcid.org/0000-0002-1577-635X
} 
system for them. In addition, it is necessary to be aware of 'why and how' FB is used by the staff. The survey method was used to collect data using a questionnaire from the selected sample using a mixed method. An applied research type was adhered to conduct the study. Findings revealed that the primary purpose of the use of FB by BPU middle-level staff was to look forward 'for news'. The behavioral study proved that there are efficient users of FB and they are capable of sharing, delivering, liking, commenting, criticizing, and uploading the posts. However, they are not proficient in creating many exciting posts. The main problem that seems to affect them is 'unknown friend requests.' It was found that there is a significant association between gender and purpose, and gender and posting authentic personnel information. It was recommended to create online 'library user groups' for communication purposes and to hold IT training sessions for middle-level staff to improve their knowledge and skills in IT usage for library related activities.

Keywords: Administrative staff, Facebook usage, Non-academic staff, Social media, User behavior 


\section{Introduction}

Social media, especially Social Networking Sites (SNS) has increased in the recent era in comparison to the past. Social media includes various web and mobile-based technologies ranging from photo and video sharing sites to rating and review forums. Social Media (SM) collect tools and online spaces available to help individuals and businesses to accelerate their information and communication needs (Lake, 2009). According to the Statcounter Global Stats web page, today's most popular social media are Facebook (FB), Twitter, Pinterest, YouTube, Instagram, blogs, RSS, and wikis. These SNS are currently a part of most internet users' day today communication. Many organizations have joined these online communities to stay connected with members and the public as communication can be done individually and group-wise.

FB is more popular than any online activity among active Sri Lankan internet users (Thuseethan \& Vasanthapriyan, 2015). Ali and Bhatti (2020); Ogaji et al. (2017), Mingle and Adams (2015) have also proved that FB is the most popular SNS in their countries as well. It was observed that the main reason for using these platforms is for sharing information. Almost $11.5 \%$ of Sri Lanka's entire population is on FB today, with 1,400,000 being male and 720,000 being female, and the age group of 2534 makes up $33 \%$ of the entire base. Furthermore, apps such as Viber, WhatsApp, and FB Messenger have changed Sri Lankans' lives by providing more accessible communication facilities. These apps have been customized with local languages and apps like Viber have been standardized and adapted among Sri Lankans' by offering chat stickers with local languages (Wijekoon, 2017). 


\section{Background of the Study}

Buddhist and Pali University (BPU) Library uses traditional communication tools to communicate with library users, student and staff, as there are no proper infrastructure facilities available to support Internetbased communication in the library currently. BPU has taken several steps recently to establish proper networking facilities at the university. Networking of library building, automation of library collection, building a digital archive, improving infrastructure facilities to conduct zoom classes, financial database, Faculty of Graduate Studies database with the support of Arthur C. Clarke Institution for Modern Technologies, are a few of them. Meanwhile, BPU recently initiated a project called the 'sustainable development' through the Ministry of Sustainable Development, Wildlife, and Regional Development. The project's primary purpose is to support a sustainable future by achieving sustainable goals (Gunasekera \& Samarakoon, 2020). The library had to initiate several activities in the library to support achieving university goals. One goal is to introduce online communication user groups to support the said project and reduce paperwork, time and labour. Local researchers (Thuseethan \& Vasanthapriyan, 2015), (Fernando, Abeysekera \& Satgunalingam, 2017) have also reported the possibility of creating such groups and their usefulness to organizations, services, and business activities.

Further, Adetayo and Williams-ilemobola also state 'In recent years, Social Media (SM) has become a new tool in the delivery of library services in a rapid and dynamic pace' (Adetayo \& Williams-ilemobola, 2021, p.3). Further, they emphasized the rapidity with which information of interest can be spread to a larger audience than traditional outlets like print media. The technology has become so popular that they now 
dominate the everyday personal and professional lives of millions of users and affect how libraries operate.

In addition, the BPU is trying to build a digital environment in the university for students and staff through several projects, and the library has to integrate membership profiles and lending activities in the future. Therefore, the BPU library needs to create different online user groups which enable easy communication. The possibility of creating such groups and their usefulness has been emphasized by Taylor and Francis (2014); Fasola (2015). Moreover, researchers indicated that the effective use of SNS would enable libraries to gain various advantages, such as the promotion of library services and new ways to render instruction. There is a need for redesigning the services to meet the demands of their users to remain relevant and retain their place as information providers in this technological era. BPU library also need to shift from traditional communication and to adopt SM in library services.

\section{Problem of the Study}

The reason for conducting this study was to understand the usage behaviour of the middle-level staff of BPU on Facebook. Without understanding the nature of the benefiter, services cannot be successfully implemented. Further, managers of this business age is faced by the challenge of how to enhance the productivity of the workforce in order to uplift profits and avoid wastage of applications based on participation and feedback that encourages free access and exchange of valuable information. With this underlying assumption, the study intends to assess whether they are active and efficient in an online environment and whether they have good communication experience. Further, the study aims to 
observe how they behave and whether they have experienced any problem when they are using, posting, and sharing information online.

Accordingly, the following research questions were compiled to address above mentioned issues.

\section{Research Questions}

i. What are the purposes of using FB by BPU middle-level staff?

ii. How does BPU middle-level staff behave on FB?

iii. What are the problems faced by the BPU middle-level staff when using FB?

iv. Is there any association between respondents' demographics and Facebook usage?

\section{Literature Review}

\section{Purpose of Using Facebook}

FB is a valuable tool to show the behaviour, both positively and negatively. Islam and Habiba (2015) pointed out that FB is a robust platform that can be extensively used online for social and professional purposes and to enhance information dissemination. The literature revealed many purposes. According to Thuseethan and Vasanthapriyan (2015) the main purpose of using FB by Sri Lankans is to get news instantly than reading weekend newspapers and more than half of Sri Lankan adults who use media sharing, blogs, microblogging, social news, and bookmarking sites also use social networks. According to Adzovie, Nyieku, and Daniel (2017), 90\% of non-academic staff use FB to improve social relationships and interactions with others, while $10 \%$ use FB for entertainment such as sharing pictures and having fun. Weerasinghe and 
Hindagolla (2018) states $58.6 \%$ of them used SNS in the workplace for "interacting with co-workers and professionals in the field", whereas 43.1\% used for "knowledge sharing". (Weerasinghe \& Hindagolla, 2018, p.36).

Jayaratne and Fernando (2014) indicated that Sri Lankan undergraduates use FB for social support and to cope with loneliness, while Aldahdouh et al. (2020) also revealed that Twitter and FB are used for personal purposes. However, according to Ali and Ahmad (2018) the principal purpose of using FB by the Pakistan LIS community is for professional updates, friend's updates, and entertainment, while economic updates and time-pass were the least preferred options. Adzovie, Nyieku and Keku (2017) indicated that $90 \%$ of administrative staff of the University of Cape Coast use Facebook to improve social relationships and interactions with others while $10 \%$ use Facebook for entertainment, sharing pictures and having fun.

\section{User Behaviour on Facebook}

Robinson (2015) indicated that SM is an attractive, prevailing, and all-encompassing means of communication that drastically affects people's interaction and behaviour. Adzovie, Nyieku, and Keku (2017) conducted a survey with non-academic staff at the University of Cape Coast on FB usage and identified that $36 \%$ of the respondents use FB occasionally, $67 \%$ of them spent less than 1 hour per day on FB and $60 \%$ daily updated their FB status 1 to 3 times daily.

Ali and Ahmad (2018) found that the frequency of FB usage is mostly daily by all demographic categories. Furthermore, a high percentage $(64.7 \%)$ of respondents indicated that Facebook to be the most 
frequently used social network site in the workplace as reported by Weerasinghe and Hindagolla (2018). According to the findings of the Ali and Ahmad (2018) majority of respondents showed their real name (93\%), gender $(98 \%)$, and age (71\%) on FB but the majority, $69 \%$ of them, have not uploaded a real photo on FB. Only $31 \%$ of them have uploaded photos on FB. Moreover, according to their findings on FB behaviour, most of them mostly expect praise or likes on their posts, but they can also accept criticism. Hence, they are also in favour of FB including an option to dislike posts. The majority of them does not create posts but mostly share others' posts. The majority of the respondents agreed that most males like female posts. However, Ali and Ahmad (2018) further reported that the respondents do not intend to please the person who posts the post and does not agree with others' point of view without any fear of criticizing. In addition, they do not put everything on FB; they also accept friends' requests that they know.

One of the adverse effects of social media or networks is an addiction (Amarakoon \& Amarakoon, 2012). Weerasinghe and Hindagolla (2018) also proved the same idea through their findings. Another downside of social media is that the user shares too much information, which may pose threats. Even with tight security settings, your personal information may leak on social sites. The other drawback is that anyone can download personnel videos or pictures, copy and convert them into different formats which is an easy task in this digital environment using just few clicks. Furthermore, when there is a problem, children no longer go to their parents for comfort or support. Instead they'd much rather vent on a social media site since social media had managed to change the comfortability of individuals that they used to have when it came to sharing their emotions. 
As a result, more people tend to be isolated from each other in the real world (Wijekoon, 2017).

\section{Problems Encountered when Using Facebook}

According to Chitumbo and Chewe (2015), the major impediments to SM adoption and usage are limited internet access points, poor internet connectivity and limited bandwidth, lack of awareness of the existing SM, lack of privacy, many SM to explore and lack of clear policy on SM tools. Sobaih et al. (2016) reported that although SM had an excellent value for academic-related purposes, particularly as a learning tool, the actual use by the academic community in Egypt was at a minimal level. Adewojo \& Mayowa-Adebara (2016) confirms that some of the significant constraints to social media usage include poor internet access with 24 (60\%), irregular power supply with 22 (55\%), and lack of social media tools 17 (42.5\%). This finding is in line with Shehu, Urhefe, and Aworo (2015), who, in their study of accessibility and utilization of internet service in Nigerian libraries, highlighted several challenges faced by the staff while accessing the internet in Nigerian libraries. The majority indicated that power outage and unavailability/ inaccessibility of internet were some of the challenges faced by the Nigerian library staff. In the same vein, studies that reported the benefits of SM use also highlighted the major constraints academic libraries are facing, such as the lack of sufficient bandwidth in Nigeria (Olajide \& Alao, 2015) and irregular power supply in Nigeria (Adewojo,

\section{A. \& Mayowa-Adebara, 2016)}

Athukorala (2018) identified barriers faced by Sri Lankans in using SM. According to Athukorala, Library staff does not have right skills to use FB. Similarly, inadequate training for library staff, slow speed of 
internet and lack of social media policies also affects SM usage. According to Amarakoon, L. \& Amarakoon, R. (2012), inadequate training opportunities, lack of knowledge, privacy and identity theft, slow speed of the internet, and electricity failure are the problems associated with applying social media in libraries of Sri Lanka for promoting library resources and services. They further recommend that library and information resource centers develop their marketing plan to utilize social media for news and service alerts and quick updates to online users (Amarakoon \& Amarakoon, 2012). According to Weerasinghe and Hindagolla (2018) many universities restricted access to Facebook and that can be identified as a problem encountered by Sri Lankan university staff when using FB. However, most of the respondents believed that the use of SM in the workplace could benefit university librarians in Sri Lanka.

\section{Methodology}

The main purpose of the study was to survey the behavior of the BPU staff community on FB. Population of the study is BPU non-academic staff.

As indicated in Table 1 below, 116 non-academic staff members are working in the university. Out of 116, 18 were lower-level workers and 12 were upper-level officers who were not included in the study sample. Available sample of 86 middle-level non-academic staff were selected as a sample for the study. Keeping in view of the nature of the study's research questions, the most appropriate research method is a survey. 


\section{Table 1}

Sample Size

\begin{tabular}{cccc}
\hline $\begin{array}{c}\text { University non-academic } \\
\text { staff categories }\end{array}$ & $\begin{array}{c}\text { Available } \\
\text { number }\end{array}$ & $\begin{array}{c}\text { Sample } \\
\text { size }\end{array}$ & $\begin{array}{c}\text { Response } \\
\text { rate }\end{array}$ \\
\hline Upper- level staff & 12 & 00 & 00 \\
Middle- level staff & 86 & 86 & $93 \%$ \\
Lower- level staff & 18 & 00 & 00 \\
Total & 116 & 86 & $93 \%$ \\
\hline
\end{tabular}

(Corporate Plan, 2019)

Since the behaviour of FB users is to be measured, a mixed-method approach and applied research type were the best suited for the study; as the findings will be applied for introducing online user groups to BPU staff.

Data collection was done using the questionnaire, which consisted of open and closed-ended questions. A hard copy of the questionnaire was hand-distributed among 86 staff members who belong to the middle level of the non-academic category in February 2020, and completed questionnaires were collected during the first week of March. Six (6) questionnaires were rejected due to non-completion of the questions. It was also observed that some questions were partly completed by respondents, which means that respondents skipped some items. However, a total number of 80 (93\%) were considered for data analysis. The data were analyzed and interpreted with the help of SPSS statistical software using simple frequency counts, and Pearson chi-square test was conducted to find association between demographic variables with the purpose of using FB and behaviour on FB by the sample. 


\section{Results of the study}

\section{Respondents' Demographic Information}

Demographic information includes the gender and age of the samples. Table 2 gives an overview of the sample. The majority (60\%) of respondents are female while males were the minority (40\%). In response to age, most respondents were between the ages $30-40$, while $36 \%$ of them were between the ages of 20-30 and $24 \%$ of them were above 40 .

\section{Table 2}

Response Rate Gender and Age Wise

\begin{tabular}{lcc}
\hline Variables & Responses & Response Rate \% \\
\hline Gender & & \\
Male & 32 & $40 \%$ \\
Female & 48 & $60 \%$ \\
Age & & \\
$20-30$ & 29 & $36 \%$ \\
$30-40$ & 32 & $40 \%$ \\
above 40 & 19 & $24 \%$ \\
& & \\
\hline
\end{tabular}

\section{Findings According to the Questions}

Question 1- What are the purposes of using FB by BPU middle-level staff?

The purposes of using FB by BPU staff were examined, as given in Table 3 below. The main purpose of using FB by $53.8 \%$ of BPU staff is 'to look forward for news.' Their (15\%) second main purpose was for 'entertainment' while the third reason indicated by $13.8 \%$ of them is 'to know what is happening worldwide'. 'To send messages to friends' was the fourth reason for using FB as indicated by $12.4 \%$ of BPU staff. 
Gender wise analysis indicated that $70.8 \%$ of females who are in the age of 20-30 use FB to look forward 'for news' while $37.5 \%$ of male staff members' purpose of using FB is for 'entertainment' but female staff members have not used FB at all for that purpose. It is also found that staff members who are aged 40 and above use FB for news but they have never used FB for the purpose of 'reducing stress'.

However, it is significant that $8.3 \%$ of female staff members are using FB 'to reduce stress' and 'to send messages to friends'. Significantly, most $(28.1 \%)$ male staff members who are in the age range of $30-40$ are using FB 'to send messages to friends, while young staff members who are in the age range 20-30 have not used FB for that purpose.

Further, analysis indicated that $40 \%$ of them are using FB for 'professional development' while $20 \%$ of them are using for 'economic information'. Very few of them use it for 'political information', 'for gossip' and 'religious information'

\section{Table 3}

Purposes of Using FB

\begin{tabular}{lcccccc}
\hline \multicolumn{1}{c}{ Attributes } & Overall & \multicolumn{2}{c}{ Gender } & \multicolumn{2}{c}{ Age } \\
\hline & $\%$ & Male & Female & $20-30$ & $30-40$ & $40<$ \\
& $53.8 \%$ & $28.1 \%$ & $70.8 \%$ & $55.2 \%$ & $43.8 \%$ & $68.4 \%$ \\
$\begin{array}{l}\text { To look forward } \\
\text { for news }\end{array}$ & & & & & & \\
$\begin{array}{l}\text { To know what is } \\
\text { happening all } \\
\text { around the world }\end{array}$ & $13.8 \%$ & $15.6 \%$ & $12.5 \%$ & $10.3 \%$ & $15.6 \%$ & $15.8 \%$ \\
$\begin{array}{l}\text { To send messages } \\
\text { to friends }\end{array}$ & $12.4 \%$ & $18.8 \%$ & $8.3 \%$ & $0.0 \%$ & $28.1 \%$ & $5.3 \%$ \\
$\begin{array}{l}\text { For entertainment } \\
\text { For }\end{array}$ & $15 \%$ & $37.5 \%$ & $0.0 \%$ & $24.1 \%$ & $9.4 \%$ & $10.5 \%$
\end{tabular}




\begin{tabular}{lrrrrrr} 
To reduce stress & $5.0 \%$ & $0.0 \%$ & $8.3 \%$ & $10.3 \%$ & $3.1 \%$ & $0.0 \%$ \\
& $100 \%$ & $100 \%$ & $100 \%$ & $100 \%$ & $100 \%$ & $100 \%$ \\
\hline
\end{tabular}

Question 2- How does BPU middle-level staff behave on Facebook?

This part of the questionnaire entailed the 20 attributes regarding behavior of respondents on FB. Table 4 shows the frequency of recorded feedback.

\section{Table 4}

Behaviour on Facebook

\begin{tabular}{|c|c|c|c|c|}
\hline & Attributes & Agree & Disagree & $\begin{array}{c}\text { Total } \\
\mathrm{n}=\end{array}$ \\
\hline 1 & I use my real name on FB & $96 \%$ & $4 \%$ & 80 \\
\hline 2 & My gender status is real on FB & $89 \%$ & $11 \%$ & 77 \\
\hline 3 & I show real age on FB & $90 \%$ & $10 \%$ & 80 \\
\hline 4 & I show my photos on FB & $96 \%$ & $4 \%$ & 77 \\
\hline 5 & $\begin{array}{l}\text { I mostly do 'wow" on interesting } \\
\text { posts }\end{array}$ & $28 \%$ & $72 \%$ & 78 \\
\hline 6 & I upload various photos on FB & $87 \%$ & $13 \%$ & 78 \\
\hline 7 & I likes' other's comments & $75 \%$ & $25 \%$ & 76 \\
\hline 8 & I like to criticize other's posts & $22 \%$ & $78 \%$ & 79 \\
\hline 9 & Mostly I expect 'likes' on my posts & $54 \%$ & $46 \%$ & 79 \\
\hline 10 & Mostly I like criticism on my posts & $40 \%$ & $60 \%$ & 78 \\
\hline 11 & Whatever I do I put on FB & $44 \%$ & $56 \%$ & 78 \\
\hline 12 & Facebook promotes happy culture & $42 \%$ & $58 \%$ & 78 \\
\hline 13 & Facebooks promotes hate culture & $24 \%$ & $76 \%$ & 78 \\
\hline 14 & $\begin{array}{l}\text { I encourage my friends to share } \\
\text { other's posts }\end{array}$ & $32 \%$ & $68 \%$ & 78 \\
\hline 15 & $\begin{array}{l}\text { I like to share other's posts than } \\
\text { posting }\end{array}$ & $96 \%$ & $4 \%$ & 78 \\
\hline 16 & I likes' other's posts & $48 \%$ & $52 \%$ & 80 \\
\hline 17 & $\begin{array}{l}\text { Mostly I like to know reactions } \\
\text { what is happening in the } \\
\text { society/country }\end{array}$ & $68 \%$ & $32 \%$ & 78 \\
\hline
\end{tabular}


$18 \quad$ I upload short form videos

$78 \%$

$22 \%$ efficiently on FB funny things

The findings indicate that $96 \%$ of BPU middle-level staff has given their real name and picture on FB, while $90 \%$ of them indicated their actual age on FB. It was also found that $89 \%$ have used their real gender on FB as indicated in Table 6 above, under the attributes 1, 2, 3, and 4 .

Further, findings revealed that most respondents disagree with attributes given under 5,8,10-14, and 16. The majority (72\%) of nonacademic staff does not like to 'wow' on exciting posts, while most (78\%) do not like to criticize other's posts. $60 \%$ of them indicated that they do not like to have criticism on their posts. Although they are active on FB, 56\% of BPU staff stated that they do not reveal whatever they do on FB. Further, the majority stated that FB neither promotes happy culture nor hate culture. The majority $(68 \%)$ of the respondents never encourage their friends to share others' posts, while $52 \%$ do not click 'likes' for other's posts. Lastly, most respondents have positive behaviour on 6,7,9, and 17-20 attributes, as indicated in Table 4 above.

\section{Table 5}

Frequency of Using Facebook

\begin{tabular}{cccccc}
\hline Variables & $\begin{array}{c}\text { According } \\
\text { to necessity }\end{array}$ & Daily & Weekly & Randomly & $\mathrm{n}=$ \\
\hline $\begin{array}{c}\text { Gender } \\
\text { Male }\end{array}$ & $38 \%$ & $48 \%$ & 0 & $14 \%$ & 31 \\
$\begin{array}{c}\text { Female } \\
\text { Age }\end{array}$ & $19 \%$ & $66 \%$ & $3 \%$ & $12 \%$ & 48 \\
$20-30$ & $28 \%$ & $62 \%$ & 0 & $10 \%$ & 29
\end{tabular}




\begin{tabular}{lllccc}
$30-40$ & $22 \%$ & $63 \%$ & 0 & $15 \%$ & 32 \\
$40<$ & $33 \%$ & $50 \%$ & $5 \%$ & $12 \%$ & 18 \\
\hline
\end{tabular}

It was found that $66 \%$ of females and $48 \%$ of male staff members, as shown in Table 5 above, use FB daily while $38 \%$ of male and $19 \%$ of female staff members are using FB 'according to necessity. Few of them (14\% and $12 \%$ ) use FB books randomly. It was also found that $3 \%$ of females are using FB weekly. 63\% of BPU non-academic staff members in the middle age range use FB daily, while $22 \%$ of them in the same age range use FB 'according to necessity'.

\section{Figure 1}

FB using time

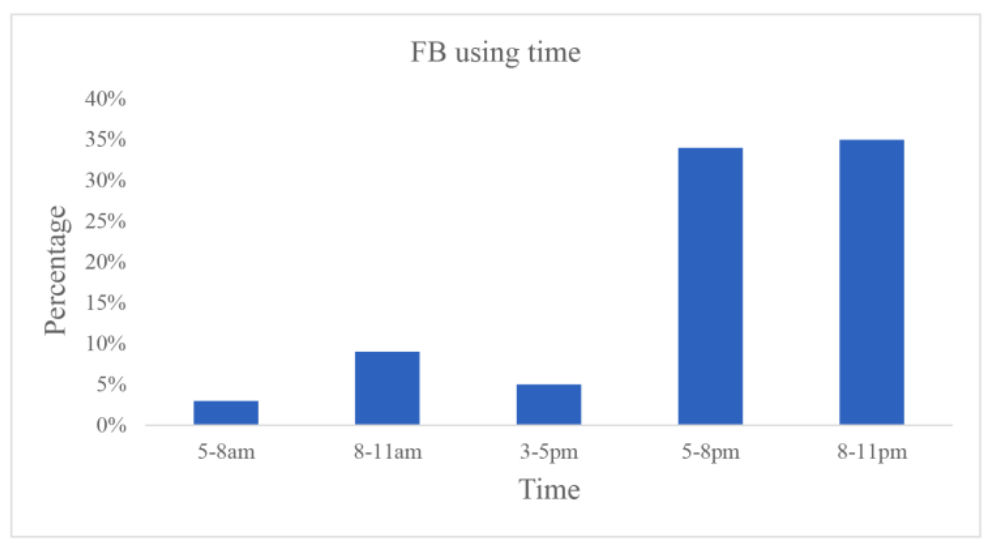

Findings indicate that $35 \%$ of BPU staff mostly use FB between 8 p.m. to 11 p.m. every day while many use it between 5 to 8 p.m. It was noted that very few of them use FB during office time, as given in Figure 1 above.

Question 3- What are the problems faced by the BPU middle-level staff when using $F B$ ? 
As shown in Figure 2 below, the main problem faced by the $23 \%$ BPU middle level staff was 'unknown friend's requests' while 'time and money waste' was the secondly affected by $19 \%$ of staff. The main problem, 'useless and needless posts sent by others' was affected by $16 \%$ of the staff while 'Fake news' being the fourth problem that affected by the $14 \%$ of them. 'Sensitive posts', slow internet speed', 'accounts checked by unknown persons,' and 'different types of ideas' were the problems that were encountered by a very few.

\section{Figure 2}

Problems affected using FB

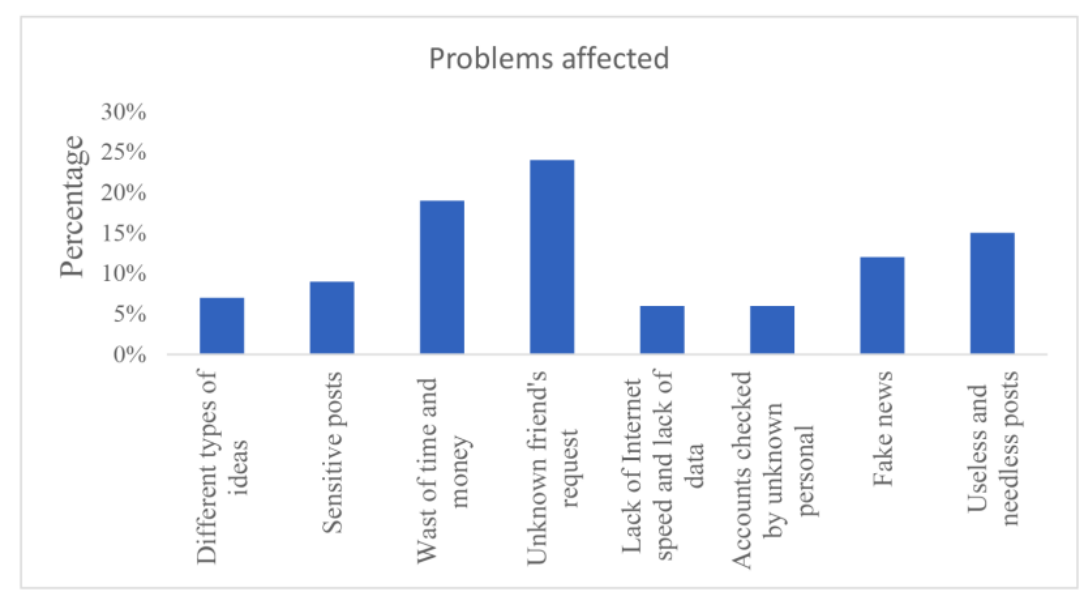

Pearson chi-square test was used to assess the association between demographic variables and purpose and behaviour to examine the relationship. The results are given as contingency tables in Tables 6 and 7 below.

Question 4 - Is there any association between respondents' demographics and Facebook usage? 
It was found that there is a significant association between purpose and gender and the purpose and age on the use of FB, as shown in Table 6 below.

\section{Association Between Gender and Purpose}

Table 6

Association Between Demographics and Purpose

\begin{tabular}{llcccc}
\hline $\begin{array}{c}\text { Demographic } \\
\text { variable }\end{array}$ & \multicolumn{1}{c}{ Attribute } & $\mathrm{N}$ & $\mathrm{df}$ & $\mathrm{X} 2$ & $\mathrm{P}$ \\
\hline Gender & $\begin{array}{l}\text { Purpose of using } \\
\text { Age }\end{array}$ & 80 & 4 & 28.985 & $0.000^{* *}$ \\
& $\begin{array}{l}\text { Pucebook } \\
\text { Facebook of using }\end{array}$ & 80 & 8 & 17.797 & $.023^{*}$ \\
\hline
\end{tabular}

** Association is significant at 0.01

* Association is significant at 0.05

\section{Association Between Gender and Behaviour}

According to the results given in table 7, only 02 associations were found as statistically significant, namely association between 'gender and the behavior attribute', 'I use my real name as FB ID' and association between 'gender and the behavior attribute' 'I show my real photo'. All the other four associations were found statistically insignificant.

\section{Table 7}

Association Between Demographics and Behavior

\begin{tabular}{lllllll}
\hline No & Behavior attributes & $\begin{array}{l}\text { Demographic } \\
\text { variable }\end{array}$ & $\mathrm{n}$ & $\mathrm{df}$ & $\chi^{2}$ & $\mathrm{p}$ \\
\hline 1 & $\begin{array}{l}\text { I use my real name as } \\
\text { FB ID }\end{array}$ & Gender & 78 & 1 & 4.992 & $.025^{*}$ \\
5 & I show my real photos & Gender & 77 & 1 & 5.167 & $.023^{*}$ \\
\hline
\end{tabular}

\footnotetext{
* Association is significant at 0.05
} 


\section{Discussion}

The use of FB has gained popularity among Sri Lankans with no geographic barriers. This network is used mainly for 'news' and for communication and information sharing in both Sri Lanka and worldwide. Due to this, professionals are adopting it and utilizing its features for various purposes and activities, as pointed out by several researchers (Sharma \& Shukla, (2016); Adewojo, A. \& Mayowa-Adebara, (2016); Essam and Mansour (2016); Singh et al., (2017) in their studies. It was found that the majority of the respondents are female and middle-aged people.

The majority of middle-level non-academic staff of BPU, including both males and females, and almost all age groups are using FB daily after office hours. These indicate that a significant number of respondents regularly logged onto FB and updated their statuses. The results are congruent with Adzovie, Nyieku, and Keku (2017), who found $36 \%$ of people $\log$ on to FB occasionally and $60 \%$ of the respondents, reported that they updated their FB statuses one to three times a day.

The main purpose of using FB varies from for news (53.8\%), for entertainment (15\%), for world news, for communicating with friends, and for reducing stress. Thuseethan and Vasanthapriyan (2015); Adzovie, Nyieku, and Daniel (2017) also reported similar purposes from their respondents.

Gender-wise analysis indicates that $70.8 \%$ of females in the $20-30$ age category used FB for 'news' while $37.5 \%$ of male staff members' purpose of using FB is 'entertainment.' The second purpose of female respondents is to know the worldwide information while for 'news' is the 
second purpose of the males. Significantly, females have never used FB for 'entertainment', and males have never used it 'to reduce the stress'. Further, findings indicated that only the females in the 20-40 age categories have used the FB to reduce stress. This may be due to the fact that females also have many responsibilities at home. They have to do a lot of planning related to home affairs after office work. Female staff members are using FB for relaxation. The results show that most of those who use FB fall in the mid-age group 20-40. These findings are in line with the findings of Thuseethan and Vasanthapriyan (2015), and it hints that the popularity of the FB among Sri Lankans has not changed even after five years in Sri Lanka. The other purposes of using FB indicated by most respondents were 'professional development, followed by 'political information'. Ali and Ahmad (2018) found similar results which indicated that the other purposes of using FB by the Pakistan LIS community is getting political and economic information. Further, it was found that few BPU middle-level staff has used FB for 'gossip', similar to the findings of Aldahdouh et al. (2020).

When considering the usage behaviour of the BPU middle-level staff on $\mathrm{FB}$, the findings indicate their honesty as the majority of respondents show their real name, gender, age, and photos in their FB profile. Further, results suggest that respondents expect 'praise or like' on their posts, but $60 \%$ of respondents reported that they do not like to criticize other's posts. However, the majority of them do not create posts but mostly share other's posts. These findings were proved by Ali and Ahamed (2018); Adzovie, Nyieku, and Keku (2017) also in their studies. When considering the question, on the frequency of behavior of the BPU staff on FB, most respondents have positive behavior on FB. They reveal their accurate 
personal information and image on FB. The majority does not like to use 'wow' on posts and do not post whatever they do on FB. Observations indicate that the behavior of the majority is the same. The majority respondents do not post every daily activity on the FB (e.g., drinking coffee, office work and personal things). Further, with regards to creation or sharing, merely around $10 \%-20 \%$ of people engage in creating posts actively, $68 \%$ of respondents believe that they want to know reactions to what is happening in society and are happy with different funny postings.

Further, most of them are of the attitude that FB does not promote hate culture and happy culture. These findings prove that university staff has neutral attitudes towards FB. They do not view it as either extremely negative or extremely positive. Instead, though they have positive attitudes towards FB, they still think that FB wastes their time and money. The majority of respondents do not mostly agree with others' points of view without fear of criticism. Most females use FB to manage stress daily after office hours. FB use by age group below 30 is likely for making new friends, religious updates, and time-pass. Further, when considering the efficiency of using FB, 95\% of them cannot upload images, photos, and videos efficiently and also communicate, share and post skillfully. In line with these findings, Weerasinghe and Hindagolla (2018) also stated that some respondents did not have enough skills to use SNS.

Most responses fall in the category termed as generally accepted or normal or positive behavior regarding the frequency of behavior attributes. The reason may be since respondents are employed and have cultured ideas and behavior. A majority of people adopting or possessing such behavior is generally a norm in an institution or society. 
The main problem faced by BPU staff was 'unknown friend's requests' while 'time and money waste' was being the second. Other problems faced by them were 'useless and needless posts sent by others', 'fake news', 'sensitive posts,' 'slow internet speed,' 'accounts checked by unknown persons' and 'different types of ideas.'

It was found that there is a significant association between purpose and gender and purpose and age on the use of FB and statistically significant association between 'gender and the behavior attribute' on the use of real name and photo on FB were also found. With regard to the association between purposes and age the problems affected the BPU staff is as same as the findings of Ali and Ahmed (2018). It is the nature of the group or mass. It can be concluded that answers for the four research questions of the study were found, and suggestions are given next section.

\section{Conclusion and Recommendations}

The main purpose of this research was to identify the usage behaviour of the BPU middle-level staff on FB to understand whether they are capable of handling information online to create online user groups to inform library-related information. Accordingly, the findings of this study confirmed the answers to the set research questions by revealing the main and other purposes, the behaviour pattern of staff on FB, problems experienced and demographic association. Hence, the findings of this study support the possibility of designing and delivering social mediabased information services at BPU for the target group.

It is suggested that the creation of user groups will be helpful and successful for BPU staff. Wi-Fi facilities should also be given to nonacademic middle-level staff after creating of user groups. Though BPU 
middle-level staff has neutral attitudes towards FB usage, it is also suggested that some restrictions on use of social media and internet use policies by employers should be imposed as it affects daily routines.

It was evident from the study's findings that most BPU middle-level staff, male and female and 20-40 age groups, are using FB daily basis at 8$11 \mathrm{pm}$. However, few of the respondents showed a usage at the working time also. All of them showed them as having 'high experience' in using FB except a few. FB usage by employees can become a strength for organizations when used to build good relationships with employees. It can be used to collect and share information about employee behaviour as well as to train them.

It is suggested that the library management should organize awareness training sessions to inform BPU staff of the implementation of the online communication system and to educate them on its usefulness and details of library-related transactions that would take place online.

The BPU staff prefers to use 'like' and comment on others' posts, but they do not like to criticize others' posts. They are able to share, deliver, like, comments, criticize, and upload the posts, but are unable to create many exciting posts. Findings revealed that $95 \%$ of them could upload images, photos, and videos efficiently and communicate, share and post skillfully. So, it can be concluded that BPU staff has positive behaviour on FB. The development of creative skills of the staff is needed for the university, and it is a motivation. So, organizing IT skill development workshops for non-academic middle-level staff is recommended.

Policymakers can develop a learning platform and a quick and costfree communication platform using these upcoming trends in technology. Then the university staff will absorb the positive aspects of these 
technologies before they use them in negative aspects. In this digital era, the provision of the correct information to the right users at the right time is a challenge for library professionals. Therefore, emerging technologies like SNS could be used as an interactive platform to communicate with library customers at a low cost. As there are no fully strengthened networking facilities at BPU, one of the problems faced by the staff is slow internet access.

Therefore, it is suggested that policymakers strengthen the networking capacity and Wi-Fi connection facility, enabling BPU staff to improve their online communication skills, breaking the traditional mode of communication.

However, FB continues to be popular, and universities are interested in increasing productivity and creating a lively working environment. It is essential for those working in higher education to familiarize themselves with FB (and other such social media platforms) and design and support interventions that meet staff expectations to help them give off their best.

Hence, it is recommended that the library management organize training sessions on the effective use of SNS to educate and train nonacademic staff of the BPU as they are an essential asset as much as the academic staff in the university.

\section{References}

Adetayo, A. \& Williams-ilemobola, O., (2021). Librarians' generation and social media adoption in selected academic libraries in Southwestern, Nigeria. Library Philosophy and Practice (e-journal), 1-22. https://digitalcommons.unl.edu/libphilprac/4984 
Adewojo, A. \& Mayowa-Adebara, O. (2016). Social media usage by library staff in academic libraries: the case of Yaba College of Technology, Lagos State, Nigeria. Information and Knowledge Management, 6 (1),43-49.

\section{https://iiste.org/Journals/index.php/IKM/article/view/28366}

Adzovie, E., Nyieku, Isaac, E., Daniel, Janet, A. (2017). Influence of Facebook usage on employee productivity: a case of university of cape coast staff, African Journal of Business Management 11(6), 110-116. https://doi.org/10.5897/AJBM2017.8265

Aldahdouh, T., Nokelainen, P., \& Korhonen, V. (2020). Technology and Social Media Usage in Higher Education: The Influence of Individual Innovativeness, SAGE Open. 10(1), 2158244019899441. https://doi.org/10.1177/2158244019899441

Ali, M., \& Bhatti, R., (2020). COVID-19 (Coronavirus) Pandemic: information sources channels for the public health awareness, Asia Pac J Public Health, 32(4), 168-169. https://doi.org/10.1177/1010539520927261

Ali, S. \& Ahmad, P. (2018). A behavioural study of Pakistan library and Information Science community on Facebook, IJoLIS,3,1-22. Amarakoon, L.R. \& Amarakoon, R.S.K. (2012). Web 2.0, Social Media and Libraries: role of social media in promoting library and information services in an academic setting: with special reference to University of Bolton, Academic Centre Sri Lanka Library. In proceedings of the NILIS Research Symposium 2012, pp. 101-115.

Athukorala, W. (2018). Challenges in adapting social media to market university libraries in Sri Lanka. International Symposium on 
Emerging Trends in Education and Library \& Information ScienceLibSym. Eastern University of Sri Lanka.

Chitumbo, E. M. M., \& Chewe, P. (2015). Social media tools for library service delivery in higher learning institutions: case of University of Zambia and National Institute of Public Administration libraries. Research Journal of Library Sciences, 3(5), 1-7.

Corporate plan: 2019-2023 (2019). Buddhist and Pali University of Sri Lanka, Homagama (unpublished document).

Essam, M. \& Mansour, E. (2016). Use of smart phone apps among library and information science students at South Valley University, Egypt. The Electronic Library, 34(3), 371-404.

Fasola, O.S. (2015). Perceptions and acceptance of librarians towards using Facebook and Twitter to promote library services in Oyo State, Nigeria. The Electronic Library, 33(5), 870-882.

\section{https://doi.org/10.1108/el-04-2014-0066}

Fernando, P.M.M., Abeysekera, Nalin \& Satgunalingam, R, (2017). The impact of social media on relationship marketing with special reference to ABC Company. Zenith International Journal of Multidisciplinary Research, 7 (2),17-26

Gunasekera, D. \& Samarakoon, M. (2020). The reflective practice for sustainable future: a case study focusing the library of Buddhist and Pali University of Sri Lanka. International Journal of Librarianship, 5(2), 45-60. https://doi.org/10.23974/ijol.2020.vol5.2.171

Islam, M. M. \& Habiba, U. (2015). Use of social media in marketing of library and information services in Bangladesh. DESIDOC Journal of Library \& Information Technology, 35(4), 299-303. 
Jayaratne, L.C.H. \& Fernando, W.M.N. (2014). Relationship between

Facebook usage and the student engagement of Sri Lankan management undergraduates. International Journal of Industrial and Manufacturing Engineerin, 8(8), 2697-2701

Lake, C., (2009). What is social media? Here are 34 definitions.

Econsultancy. https://econsultancy.com/what-is-social-media-hereare-34-definitions/

Mingle, J., \& Adams, M. (2015). Social media network participation and academic performance in senior high schools in Ghana. Library Philosophy and Practice, (e-journal). Paper 1286.

Ogaji , Ikoni J., Paula C.Okoyeukwu, Irene WanjiruWanjiku, Edith AdhiamboOsiro \& Diana AkothOgutu (2017). Pattern of use of social media networking by Pharmacy students of Kenyatta university, Nairobi, Kenya. Computers in Human Behavior,66, 211-216. https://doi.org/10.1016/j.chb.2016.09.035

Olajide, A., \& Alao, A. (2015). Social media space presence: A review of Nigerian universities on social media space. In. the African Symposium. Journal of the African Educational Research Network, 15(1), 98-106.

Robinson, M. (2015). How an induction year can make all the difference to novice teachers conversation Africa, Chicago: Chicago Press.

Sharma, A. \& Shukla, A. K. (2016). Impact of social messengers especially WhatsApp on Youth-a sociological study. International Journal of Advance Research and Innovative Ideas in Education, 2(5), 367-375.

Shehu, H., Urhefe, E.A. \& Aworo, P. (2015). Accessibility and utilization of internet service in Nigeria libraries: an empirical study. 
International Journal of Academic Research and Reflection, 3(5),7889.

Singh, Monica Munjial, Amiri, Mohammad \& Sabbarwal, Sherry, Social media usage positive and negative effects on the life style of Indian Youth (2017). Iranian Journal of Social Sciences and Humanities Research, 5, (3). https://ssrn.com/abstract=3419551

Sobaih, A. E. E., Moustafa, M. A., Ghandforoush, P. \& Khan, M. (2016). To use or not to use? Social media in higher education in developing countries. Computers in Human Behavior, 58, 296-305.

Statcounter: Global Stats, Retrieved 6 April 2020, from https://gs.statcounter.com/social-media-stats/all/sri-lanka/\#monthly201903-202003

Taylor \& Francis (2014). Use of social media by the library: current practices and future opportunities. While Papers, Taylor \& Francis. https://doi.org/10.6084/m9.figshare.1221673.v1

Thuseethan, S. \& Vasanthapriyan, S. (2015). Social media as a new trend in Sri Lankan digital journalism: a surveillance, Asian Social Science, 11 (10), 86-93. https://www.ccsenet.org/journal/index.php/ass/article/view/47756

Weerasinghe, S. \& Hindagolla, B.M.M.C.B. (2018).Use of Social Network Sites (SNS) by library academics in the workplace: perspectives of university librarians in Sri Lanka. Journal of the University Librarians Association of Sri Lanka, 21 (2), 21-43. https://doi.org/10.4038/jula.v21i2.7916

Wijekoon, A. S. (2017). Comparative analysis on social media and its positive and negative impact on Sri Lankan culture. International 
Journal of the University Librarians Association of Sri Lanka, Vol. 25, Issue 1, January 2022, 55 83, DOI: http://doi.org/10.4038/jula.v25i1.8053

Journal of Research in Economics and Social Sciences (IJRESS), 7

(2), 180-185. http://euroasiapub.org 